\title{
Human Capital and Development
}

\author{
Rodolfo E. Manuelli
}

Perhaps no question has attracted as much attention in the economics literature as "Why are some countries richer than others?" In this article, the author revisits the "development problem" and provides some estimates of the importance of human capital in accounting for cross-country differences in output per worker. His results suggest that human capital has a central role in determining the wealth of nations and that the quality of human capital varies systematically with the level of development. (JEL E00, O040)

Federal Reserve Bank of St. Louis Review, Third Quarter 2015, 97(2), pp. 197-216.

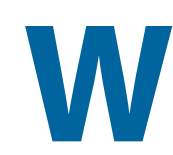
hy are some countries richer than others? This question is central to the current research agenda in economics. The difference in output per worker between "rich" countries (defined as the top 10 percent of countries in terms of labor productivity) and "poor" countries (the bottom 10 percent) is very large: The productivity of a typical worker in a poor country is about 2 percent of the productivity of a worker in a rich country. It is only natural to try to understand the factors accounting for this gap and, more importantly, whether this understanding provides some guidance about the types of policies that can help poor countries improve their economic situation. Put differently, economists (and policymakers) would like to find the "engine of growth."

In this article, I describe some recent research on the role of human capital in accounting for the cross-country differences in output per worker. One key feature of this approach to the development problem is its emphasis on viewing human capital as two-dimensional with both a qualitative and a quantitative component. Thus, in this view of human capital as a central factor in explaining differences in output per worker, the amount of human capital of a high school graduate from, say, Rwanda need not be the same as the amount of human capital of a U.S. high school graduate. In what follows, I discuss the role and quantitative importance of human capital in accounting for a country's level of development.

Rodolfo E. Manuelli is the James S. McDonnell Distinguished University Professor in the Department of Economics at Washington University in St. Louis and a research fellow at the Federal Reserve Bank of St. Louis. Lowell Ricketts provided research assistance.

@ 2015, Federal Reserve Bank of St. Louis. The views expressed in this article are those of the author(s) and do not necessarily reflect the views of the Federal Reserve System, the Board of Governors, or the regional Federal Reserve Banks. Articles may be reprinted, reproduced, published, distributed, displayed, and transmitted in their entirety if copyright notice, author name(s), and full citation are included. Abstracts, synopses, and other derivative works may be made only with prior written permission of the Federal Reserve Bank of St. Louis. 


\section{Figure 1}

\section{Average Years of Schooling and Real Output per Worker (by decile)}

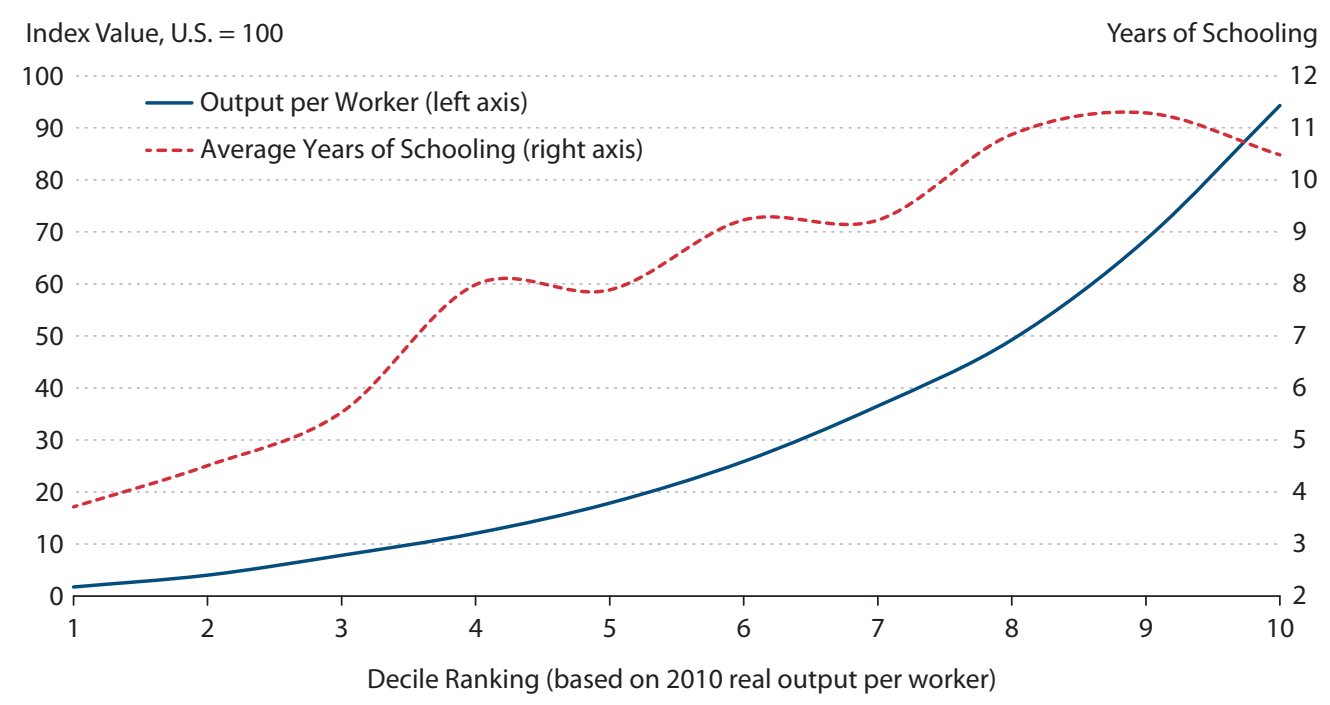

SOURCE: Penn World Table (version 8.0; http://www.rug.nl/research/ggdc/data/pwt/) and Barro and Lee (2010).

\section{EVIDENCE}

Figure 1 shows some aggregate data for all the countries in the world, circa 2010, grouped by deciles according to their level of output per worker. The average country in the top decile (the average rich country) has an output per worker that is almost 95 percent of the U.S. level. In contrast, a worker in the median country-the average country in the 5th to 6th decileproduces about one-quarter of the amount produced by a U.S. worker; this ratio drops to 1.7 percent for the typical worker in a poor country.

What accounts for these output differences? Figure 1 also displays the average years of schooling for the typical worker, and a clear pattern is evident: Richer countries have a moreeducated labor force. Figure 2 shows two other measures correlated with output per worker: life expectancy at 5 years of age and total fertility rate. There is a clear association between these variables and development: Richer (more productive) countries have a better-educated workforce that is, on average, healthier (as measured by life expectancy) and has a lower fertility rate.

It is tempting to view this evidence as a recipe for growth. Looking at the data, it seems that if only countries had more successful educational systems, better health care, and some form of birth control, this combination would result in potentially large increases in output per worker. This approach ignores the fact that individuals in every country make their own choices about schooling, health care, and fertility. Thus, to induce changes in any of these variables it is necessary to understand the forces and constraints that account for the observed pattern of human capital investment. 


\section{Figure 2}

\section{Life Expectancy at Age 5 and Total Fertility Rate}

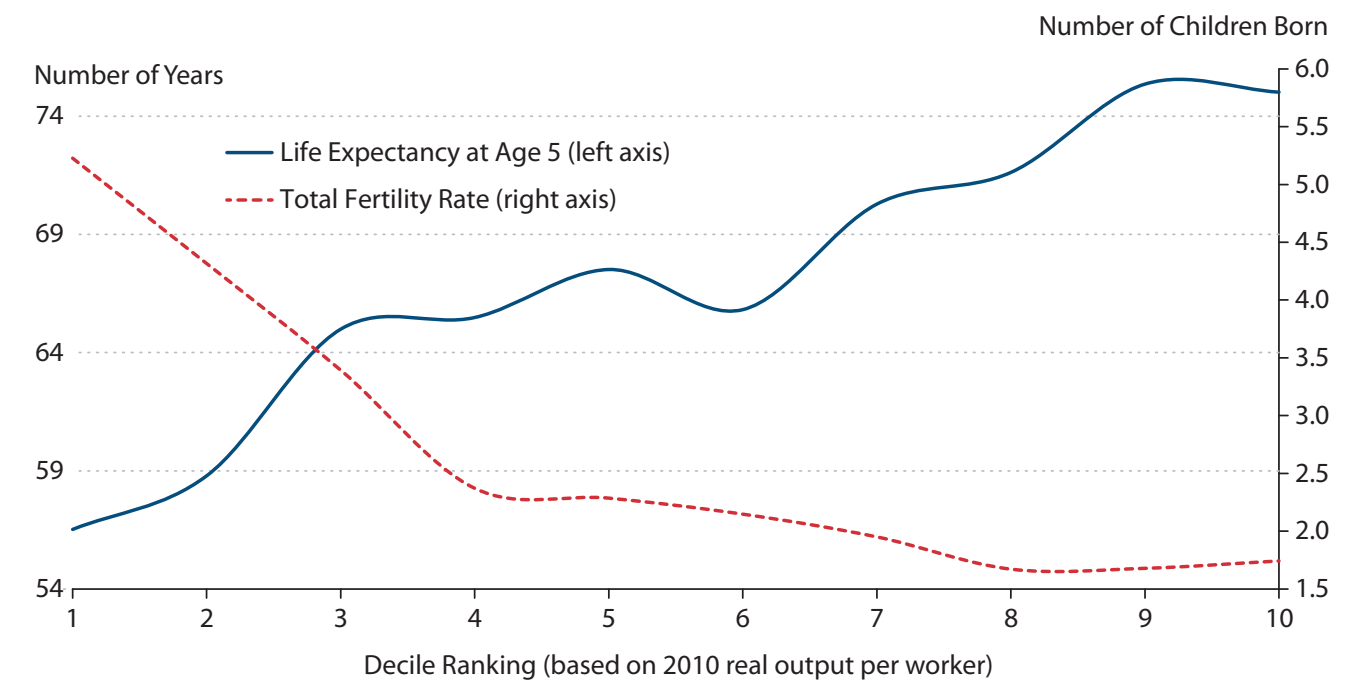

SOURCE: Data from United Nations (2013).

A reasonable starting point on the question of development (or lack of it) seems to be to ask the following question: "What factors induce individuals in poor countries (the bottom 10 percent in productivity) to attend school for only 3.7 years, to have almost 5.2 children per woman, and to live in an environment where life expectancy at 5 years of age falls short of 57 years?" These circumstances are in contrast to those of the average individual in a rich country: almost 11 years of schooling, only 1.7 children per woman, and a life expectancy (at age 5) of 75 years. To find solutions to bettering the poor country's scenario, it is necessary to develop a model that captures how individuals make choices about schooling, fertility, and health care and how factors that are exogenous (to them) influence those choices.

\section{A SIMPLE APPROACH}

As a starting point, I study a simple model that captures the aggregate impact of schooling and, more generally, human capital accumulation decisions. The model includes differences in both the quantity of human capital (measured as years of schooling, the red line in Figure 1) and the quality of human capital (which can be measured only very indirectly). Even though including human capital quality in the calculations complicates the interpretation of the results - as quality is not directly observable-I argue that explicitly accounting for quality differentials is essential to explaining the data in Figure 1.

Consider the simplest (and somewhat unrealistic) model: Individuals do not choose their schooling, and the quality of schooling is the same in all countries. Several estimates (e.g., 
those of Bils and Klenow, 2000, and Psacharopoulos and Patrinos, 2004) show the impact of education: An additional year of schooling increases individual income about 10 percent. ${ }^{1}$ In this case, and absent differences in quality, the level of human capital per worker in country $i$, defined as the return to schooling, is

$$
h_{i}=h^{q} e^{r_{s} s_{i}},
$$

where $r_{s}$ is the rate of return to schooling $\left(r_{s}=0.10\right.$ in this example), $s_{i}$ is years of schooling, and $h^{q}$ is a constant that captures the common quality level of schooling.

I consider a simple technology to develop a framework adequate to understanding the differences in the level of output per worker. This technology maps capital per worker, $k$, human capital per worker, $h$, and total factor productivity (TFP), which is denoted by $z$, into output per worker. The standard in the macro literature is the Cobb-Douglas specification that states that output per worker is given by

$$
y_{i}=z_{i} k_{i}^{\alpha} h_{i}^{1-\alpha}, \quad 0<\alpha<1
$$

As a first pass, assume that all countries face the same cost of capital, $r^{*}$, and that firms choose the level of capital to equate its cost to its marginal product. Formally, this requires that

$$
r^{*}=\alpha z_{i} k_{i}^{\alpha-1} h_{i}^{1-\alpha}
$$

which implies that the capital-to-human capital ratio is

$$
\frac{k_{i}}{h_{i}}=\left(\frac{\alpha z_{i}}{r^{*}}\right)^{\frac{1}{1-\alpha}}
$$

and, hence, that output per worker is

$$
y_{i}=z_{i}\left(\frac{\alpha z_{i}}{r^{*}}\right)^{\frac{\alpha}{1-\alpha}} h_{i} .
$$

Thus, in this view, the differences in output per worker are driven by differences in TFP, $z_{i}$, and differences in human capital per worker, $h_{i}$. To match the data in Figure 1, it is convenient to express output per worker in country $i$ as a ratio of the U.S. level. The ratio for the average poor country, where output per worker is about 1.7 percent of that in the United States, which is normalized to 1 , is expressed as

$$
\frac{1}{0.017}=\frac{y_{R}}{y_{P}}=\left(\frac{z_{R}}{z_{P}}\right)^{\frac{1}{1-\alpha}} \frac{h_{R}}{h_{P}} .
$$

If the average worker in a poor country has 3.7 years of schooling, $s_{P}=3.7$, and the average worker in the United States has 14 years of schooling, $s_{R}=14$, equation (1) can be used to estimate human capital per worker in each country. In this case, I find that $h_{R} / h_{P}=2.8$. If $\alpha=1 / 3$, 
which is a standard estimate of capital share, then the estimate of the (unexplained) differences in productivity is

$$
\frac{z_{R}}{z_{P}}=\left(\frac{1}{0.017} \times \frac{1}{2.8}\right)^{2 / 3}=7.6
$$

According to these calculations, the productivity of the average firm in a poor country is about 13 percent of the productivity of an average U.S. firm. It is this type of calculation that led Parente and Prescott (2000) to dismiss human capital as a major force in accounting for differences in productivity. ${ }^{2}$

Is this a reasonable productivity estimate? It implies that, given the same type of equipment and "effective" labor input (measured as individuals with a given level of schooling), there are some country-specific environmental factors that result in U.S. inputs yielding a productivity level more than seven times the level in a poor country. This is a large difference that seems to exceed the micro estimates.

How would these calculations - and the estimate of the TFP gap-change if the quality of human capital differed across countries? To capture this idea, I modify equation (1) and add a qualitative component. Formally, the level of human capital per worker is given by

$$
h_{i}=h_{i}^{q} e^{r_{s} s_{i}},
$$

where $h_{i}^{q}$ is the quality of human capital in country $i$ for a given level of schooling. In this case, the estimates of the differences in productivity (paralleling the previous calculation) yield

$$
\frac{z_{R}}{z_{P}}=\left(\frac{1}{0.017} \times \frac{1}{2.8}\right)^{2 / 3} \frac{h_{P}^{q}}{h_{R}^{q}}
$$

and, hence, the higher the quality gap (i.e., the smaller the ratio $h_{P}^{q} / h_{R}^{q}$ ), the smaller the estimated differences in productivity.

At this point, the simple approach suggests that explaining differences in output requires understanding why individuals in a poor country acquire less schooling than individuals in a rich country (i.e., why is $s_{P}<s_{R}$ ?) and, if possible, determining (and estimating) the differences in quality (i.e., $h_{P}^{q}$ and $h_{R}^{q}$ ).

A significant amount of research in macro development has been directed toward developing models that explain individual choices along the quantity (e.g., schooling) and quality dimensions.

In this discussion, I ignore the differences in the price of capital, which imply differences in the rental price of capital $r^{*}$, as a potential determinant of cross-country differences in labor productivity. Even though the simple theory sketched above (see equation (2)) implies that the cost of capital influences output per worker, the evidence shows no clear pattern: Capital is relatively cheap in the top two deciles but shows no clear trend across the world distribution. Even though I ignore these differences in the description of the forces that determine the variability of output per worker, I include the impact of differences in the price of capital in the quantitative exercise that follows. 


\section{MACROECONOMIC ENVIRONMENT AND HUMAN CAPITAL}

Moving beyond simple calculations makes it necessary to be explicit about which features of an economic environment could potentially induce individuals to (i) choose more or less schooling (and on-the-job training [OJT]) and (ii) select different qualities of both education and knowledge acquired on the job. In this section, I show that cross-country differences in productivity can result in cross-country differences in schooling and human capital. To this end, I describe a simplified model of the simultaneous choice of schooling quantity and quality as well as OJT. ${ }^{3}$

I assume that accumulation of human capital during the schooling period satisfies

$$
\dot{h}(a)=z_{h} h(a)^{\gamma_{1}} x_{s}^{\gamma_{2}} \text {, with } \gamma=\gamma_{1}+\gamma_{2} \in(0,1)
$$

where $x$ is the amount of market goods (i.e., teachers, buildings, textbooks) allocated to education and $h(a)$ is the level of human capital that an $a$-year-old student possesses. ${ }^{4}$ The parameter $z_{h}$ corresponds to innate ability, and the specification captures the idea that students with higher ability are better able to turn school resources into knowledge. Finally, the restriction that $\gamma \in(0,1)$ is consistent with the view that there exist decreasing returns to scale in education. In addition to the accumulation of human capital attained in school, children at age 6 enter the school system with a certain level of human capital, denoted $h_{E}$, which I view as early childhood human capital.

If a student stays in school for $s$ periods and the school quality is $x_{s}$, his level of human capital at the end of schooling is given by

$$
h(s)=\left[h_{E}^{1-\gamma_{1}}+\left(1-\gamma_{1}\right) z_{h} x_{s}^{\gamma_{2}} s\right]^{\frac{1}{1-\gamma_{1}}} .
$$

This specification shows that for a given level of schooling, $s$, individuals who either have a higher level of early childhood human capital (higher $h_{E}$ ) or attend higher-quality schools (higher $x_{s}$ ) have a higher level of human capital. Thus, schooling and human capital need not be perfectly correlated as the relative cost of time and goods varies across countries.

So far, I have taken both the quality and the quantity of schooling as given, but in any reasonable model they should be endogenous. To develop a theory of how individuals choose both dimensions of schooling, it is necessary to be explicit about their objectives. In this article, and as a first approximation, I assume that individuals maximize the present discounted value of their lifetime income. ${ }^{5}$

With this view, an individual chooses the length of schooling, $s$, and the quality of schooling, $x_{s}$, to maximize the discounted value of lifetime income. As an intermediate step, consider the problem solved by an individual after leaving school and joining the workforce. If the discount rate (interest rate) is $r$, the worker chooses how to allocate time and goods to solve

$$
V(h, s)=\max _{x, n} \int_{s}^{R} e^{-r(a-s)}\left[w h(a)(1-n(a))-x_{w}(a)\right] d a,
$$

subject to 


$$
\dot{h}(a)=z_{h}[n(a) h(a)]^{\gamma_{1}} x_{w}(a)^{\gamma_{2}}-\delta_{h} h(a), \quad a \in(s, R),
$$

where a fraction $n(a)$ of the time is devoted to OJT and, hence, $1-n(a)$ is the effective fraction of the time that the worker allocates to producing. Here, $x_{w}(a)$ is the amount of market goods used in the production of human capital, $R$ is the retirement age, and $w$ is the wage per unit of human capital. ${ }^{6}$ The specification of the OJT technology (equation (5)) views the process of acquiring more human capital as one that uses time on the job given a level of human capital, $n(a) h(a)$, and material resources, $x_{w}(a)$, to increase a worker's human capital. For example, if an individual spends an hour per day learning to use a computer program, $n(a)$ would be approximately $1 / 8$ and $x_{w}(a)$ is the value of the resources (services of computers, buildings, and supervisor's time) used in the process.

It is possible to show (see the appendix) that the solution to the income maximization problem, given $h(s)$ is

$$
V(h(s), s)=w \frac{m(s ; r)}{r+\delta_{h}} h(s)+w^{\frac{1-\gamma_{1}}{1-\gamma}} C \int_{s}^{R} e^{-r(t-s)} m(t ; r)^{\frac{1}{1-\gamma}} d t
$$

where

$$
m(t ; r)=1-e^{\left(r+\delta_{h}\right)(R-t)}
$$

is a discount factor and $C$ is a constant.

It is useful to note the lifetime pattern of the effective labor supply implied by this model. The effective labor supply-that is, labor supplied to the market-is $h(a)(1-n(a))$. It is possible to show that these two endogenous choices have the following properties:

(i) The level of human capital, $h(a)$, initially increases and peaks at some intermediate age; thereafter, it decreases very slightly until retirement.

(ii) The fraction of the time allocated to production, $1-n(a)$, increases over an individual's lifetime and is close to 100 percent of the workweek when a worker reaches middle age.

These two properties of the solution imply that a young worker supplies less human capital than a middle-aged worker because of differences in OJT even if both workers have exactly the same level of formal education. The simple model outlined previously is consistent with the observation that the curve for income earned by an individual over a lifetime has an inverted- $U$ shape.

How should this income-maximizing individual choose the schooling variables? Consistent with the view that economic agents maximize lifetime income, an individual chooses the length of the schooling period, $s$, and the quality of schooling, $x_{s}$, to maximize the net present value of income,

$$
\max _{x_{s} s} V(h(s), s)-\frac{e^{r s}-1}{r} x_{s},
$$

subject to 


$$
h(s)=\left[h_{E}^{1-\gamma_{1}}+\left(1-\gamma_{1}\right) z_{h} x_{s}^{\gamma_{2}} s\right]^{\frac{1}{1-\gamma_{1}}} .
$$

It is possible to show that under reasonable parameter restrictions the solution has the property that both quantity (as measured by $s$ ) and quality (as indexed by $x_{s}$ ) increase with wages.

It is relatively simple to relate wages - the proximate driver of individual choices of schooling and quality of human capital-to aggregate productivity. If the production function of goods is Cobb-Douglas, the wage rate per unit of human capital in country $i$ is

$$
w_{i}=z_{i}\left(\frac{\alpha z_{i}}{r^{*}}\right)^{\frac{\alpha}{1-\alpha}}
$$

which is increasing in productivity.

It follows that in countries with high productivity (i.e., high $z_{i}$ ), the return to human capital is higher and, as a consequence, workers in such countries choose more and better schooling. Thus, this more general view has two important implications. First, it can potentially reconcile the macro estimates of differences in output per worker with the micro estimates of productivity differentials. Second, it can provide a measure of the amplification impact of increases in productivity on both levels of schooling and quality.

Before I can use the model to make quantitative predictions, it is necessary to describe how output per worker depends on features of the economy. As assumed earlier, total output depends on total capital, $K(t)$, and total effective human capital, $H^{e}(t)$. If the population is growing at rate $\gamma$ and if expected lifetime is $T$, it follows that the number of individuals of age $a$ at time $t$ is

$$
\eta(a, t)=\frac{\gamma}{1-e^{-\gamma T}} e^{-\gamma a} N(t)
$$

where $N(t)$ is the population size at time $t$. The size of the workforce, $F(t)$ is the number of individuals between the ages of $s$ and $R$. Thus,

$$
F(t)=\frac{\gamma}{1-e^{-\gamma T}}\left(\int_{s}^{R} e^{-\gamma a} d a\right) N(t)=\frac{e^{-\gamma s}-e^{-\gamma R}}{1-e^{-\gamma T}} N(t),
$$

and average effective human capital per worker is

$$
\bar{h}^{e}(t)=\frac{H^{e}(t)}{F(t)}=\frac{\gamma}{e^{-\gamma s}-e^{-\gamma R}} \int_{s}^{R} h(a)(1-n(a)) e^{-\gamma a} d a .
$$

Output per worker is then

$$
y(t)=z_{i} k(t)^{\alpha}\left(\bar{h}^{e}(t)\right)^{1-\alpha},
$$

where 


$$
k(t)=\frac{K(t)}{F(t)}
$$

is capital per worker.

Equation (6) reveals that, in addition to the impact of productivity differences on individual choices of schooling (both quantity and quality) and OJT, differences in population growth rates across countries, $\gamma$, mortality, $T$, and retirement, $R$, have a direct impact on output. It is particularly interesting that in countries with a fast-growing population, a relatively large fraction of their workforce is "young"; and since young individuals have lower human capital than middle-aged individuals in this model, the average level of human capital is lower relative to countries with slow population growth.

The model just described can be generalized, allowing for (i) an endogenous choice of early childhood human capital (chosen by parents and related, principally, to health) and (ii) limitations on the effective working lifetime as the result of expected mortality. Generalizations along these lines are reported by Manuelli and Seshadri (2014).

\section{DEVELOPMENT ACCOUNTING}

In this section, I explore the consequences of the assumption that individuals respond to economic incentives when they accumulate human capital and to what extent it changes the relatively large estimates of the productivity gap between rich and poor countries found earlier. To this end, I use a version of the model described previously to estimate productivity in the average country of each decile of the world income per worker distribution. To be precise, I take demographic variables, $\psi$ (total fertility rate), $T$ (life expectancy), $R$ (retirement age), and the price of capital $\left(p_{k}\right)$, for the average country in each decile as given, and I choose the level of TFP for each decile (the $z$ variable) so that the model's predictions for output per worker match the data. However, this specification does not constrain the predictions of the model regarding years of schooling and expenditures on education-a rough measure of quality-to be consistent with the data. One way to evaluate the performance of this theoretical framework is to compare its predictions about the unconstrained variables-schooling and expenditureswith the data.

Table 1 presents the predictions of the model and the data for both schooling, $s$, and the fraction of output allocated to educational expenditures, $x_{s}$. For these two variables, Table 1 reports both the actual values-labeled "Data" - and the predictions of the model.

The model performs fairly well in matching the two variables that it predicts: schooling and expenditures in formal education. The predictions for schooling are close to the data, although they tend to overpredict educational attainment for the richer set of countries. In terms of a rough measure of quality such as schooling expenditures (measured as a fraction of output), the model actually underpredicts investment at the high end of the world income distribution and slightly overpredicts expenditures for the poor countries.

The most striking results are the estimates of TFP. In this model, TFP in the poorest countries (i.e., countries in the lowest decile of the world income distribution) is estimated to be 


\section{Table 1}

Output and Schooling: Data and Model

\begin{tabular}{|c|c|c|c|c|c|c|}
\hline \multirow[b]{2}{*}{ Decile } & \multirow{2}{*}{$\frac{y}{\text { Relative to U.S. }}$} & \multirow[b]{2}{*}{$\operatorname{TFP}\left(z_{i}\right)$} & \multicolumn{2}{|c|}{$s$} & \multicolumn{2}{|c|}{$x_{s}$} \\
\hline & & & Data & Model & Data & Model \\
\hline $90-100$ & 0.872 & 0.97 & 10.36 & 11.68 & 5.1 & 3.2 \\
\hline $80-90$ & 0.743 & 0.95 & 9.77 & 11.50 & 5.7 & 3.7 \\
\hline $70-80$ & 0.508 & 0.94 & 9.79 & 10.32 & 4.6 & 2.5 \\
\hline $60-70$ & 0.348 & 0.92 & 8.79 & 9.47 & 4.7 & 3.3 \\
\hline $50-60$ & 0.251 & 0.91 & 8.45 & 8.70 & 3.9 & 3.0 \\
\hline $40-50$ & 0.187 & 0.81 & 6.29 & 8.49 & 4.6 & 4.0 \\
\hline $30-40$ & 0.125 & 0.85 & 7.64 & 7.06 & 4.7 & 4.0 \\
\hline $20-30$ & 0.077 & 0.79 & 5.18 & 5.98 & 3.8 & 5.2 \\
\hline $10-20$ & 0.037 & 0.71 & 3.61 & 4.25 & 4.6 & 5.8 \\
\hline $0-10$ & 0.019 & 0.63 & 2.75 & 2.83 & 3.6 & 4.3 \\
\hline
\end{tabular}

\section{Table 2}

\section{Understanding Human Capital Differences}

\begin{tabular}{lccccccc} 
& \multicolumn{3}{c}{ Relative to U.S. } & & \multicolumn{3}{c}{ Contribution (shares) } \\
\cline { 2 - 4 } Decile & $y$ & $h_{E}$ & $\bar{h}$ & & OJT & Schooling & Early childhood \\
\hline $90-100$ & 0.872 & 0.93 & 0.90 & & 0.43 & 0.48 & 0.08 \\
$50-60$ & 0.251 & 0.67 & 0.41 & & 0.45 & 0.42 & 0.13 \\
$0-10$ & 0.019 & 0.28 & 0.05 & & 0.32 & 0.24 & 0.44
\end{tabular}

63 percent of U.S. TFP. This is in stark contrast to the results of Parente and Prescott (2000), Hall and Jones (1999), and Klenow and Rodriguez-Clare (1997), who find that large differences in TFP are necessary to account for the observed differences in output per worker. By comparison, the corresponding number in their studies is around 25 percent, and my estimate from the naive exercise is 14 percent. Thus, my estimate of TFP in the poorest countries is more than two and a half times higher.

If one uses the model to compute the elasticity of output with respect to TFP when all endogenous variables are allowed to reach their new steady state (over the very long run), my estimate of this elasticity is around 5.7. Thus, according to the model, changes in TFP have a large multiplier effect on output per worker (Table 2). ${ }^{7}$

The practical implication of this finding is that, once differences in the quality of human capital are allowed for, standard macro models appear more consistent with the micro evidence, which suggests that the differences in productivity at the micro level between rich and poor countries are not very large. It also implies that small improvements in productivity will have large effects on long-run output, but these improvements will require increases in both the quantity and the quality of schooling. 


\section{Human Capital Quality}

How large are the model-implied differences in the average quality of human capital between rich and poor countries? The conceptual exercise is to determine the differences in human capital between two workers in different countries once the schooling component has been netted out.

The model I discuss implies that the human capital of the average worker in the lowest decile is only 7 percent of the human capital of the average worker in the United States. Part of that difference is driven by differences in schooling, but differences in quality (i.e., differences in $h_{i}^{q}$ ) are also significant. Using the estimates, I find that

$$
\frac{h_{P}^{q}}{h_{U S}^{q}}=0.17
$$

which implies that the quality of human capital is much lower in poor countries. To be precise, the average qualitative component of the human capital of a worker in the bottom 10 percent of the world income distribution is only 17 percent of that of a U.S. worker. Thus, not only do U.S. workers have significantly more schooling, but they also have better schooling (and OJT). In addition, the U.S. workforce is older and, hence, has more experience (OJT) and this contributes to the quality differentials.

\section{The Importance of Early Childhood and On-the-Job Training}

It is instructive to decompose the differences in average human capital per worker into three components: early childhood, schooling, and OJT. The model implies that, even at age 6, there are substantial differences between the human capital of the average child in rich and poor countries. Table 2 presents the values of human capital at age $6\left(h_{E}\right)$ and aggregate human capital per worker $\left(\bar{h}^{e}\right)$ for three deciles relative to those of the United States. The values imply that only 8 percent of the human capital for the average worker in a rich country is acquired before 6 years of age, while the contribution of early childhood human capital is 44 percent for the average worker in a poor country. This large difference is driven by two factors. First, differences in health and nutrition imply differences in human capital at age 6. Second, in rich countries workers tend to be older and acquire significantly more human capital over their lifetimes, whereas in poor countries the average worker is much younger-and, hence, has not had the time to accumulate human capital-and invests less in schooling and OJT.

According to the model, OJT is an important source of human capital. In rich countries it accounts for 43 percent of all the available human capital and even in poor countries it represents 32 percent of the total. The results suggest that policies that influence OJT can have a potentially large impact of output per worker.

\section{DEMOGRAPHICS AND DEVELOPMENT}

The evidence described previously shows that rich and poor countries differ in terms of their demographic structure, and this plays an important role in terms of estimating the level 
of human capital per worker. The reason is simple: Countries with high fertility rates are also countries in which the labor force is relatively young. This, in turn, implies that the amount of human capital per worker is small since human capital increases over the lifetime as a result of investment in OJT.

\section{A Simple Demographic Change Experiment}

One could use the model to ask the following question: What would happen to the level of output per worker in the poorest country (lowest decile) if that country had the demographic parameters (e.g., the same fertility and mortality rates) of the United States? To answer this question, I use the model to perform a theoretical exercise and calculate the estimated productivity of the average country in the lowest decile (63 percent of the U.S. productivity) if that country had the U.S. demographic variables. To be precise, I estimate the impact on output per worker if the average woman had 1.7 children instead of 5.2 and the life expectancy at age 5 was increased from 56 to 80 years.

I find that this shift in demographic variables would result in a 53 percent increase in output per worker. According to the model, this increase in output is accompanied by a 26 percent increase in the level of schooling (from 2.83 to 3.59 years of schooling for the average worker). In this experiment, demographic change drives both schooling and output. Thus, the model is consistent with the view that changes in fertility can have large effects on output. It is important to emphasize that these quantitative estimates reflect long-run changes. The reason is that the changes in demographic variables assume that the level of human capital has fully adjusted to its new steady-state level. Given the generational structure, this adjustment can take a long time.

\section{Endogenous Fertility and Mortality}

Because demographic variables play such a large role in output, it is of interest to "force" the model to account for the fertility choices made by individuals in poor and rich countries. Following the work of Barro and Becker (1989), Manuelli and Seshadri (2009) extend this human capital model and explicitly account for the cost of raising children and the fact that, in poor countries, children are also a source of labor and income.

To be precise, the basic model described previously must be enriched with fertility and health investment choices. Individuals are assumed to choose the number of children, $f$, along the lines of Barro and Becker (1989) and to care about the welfare of their descendants. There is a technology to "produce" life expectancy, $T(g)$, which uses market goods, $g$. This is a simple way to capture the potential life expectancy effect of resources devoted to sanitation, health care infrastructure, and other investments that influence health.

Formally, the utility function of a parent who has $h$ units of human capital and a bequest equal to $b$ at age $I$ is given by

$$
W^{P}(h, b, g)=\int_{I}^{T(g)} e^{-p(a-I)} u(c(a)) d a+e^{-\alpha_{0}+\alpha_{1} f}
$$




$$
\int_{0}^{I} e^{-\rho(a+B-I)} u\left(c_{k}(a)\right) d a+e^{-\alpha_{0}+\alpha_{1} f} e^{-\rho B} W^{k}\left(h_{k}(I), b_{k}, g_{k}\right) .
$$

Thus, the contribution to the parent's utility of an $a$-year-old child still dependent on him is $e^{-a_{0}+a_{1} f} e^{-\rho(a+B-I)} u\left(c_{k}(a)\right)$, since at that time the parent is $a+B$ years old. In this formulation, $e^{-a_{0}+a_{1} f}$ captures the degree of altruism. If $a_{0}=0$, and $a_{1}=1$, this is a standard infinitively lived agent model. Positive values of $a_{0}$ and values of $a_{1}$ less than 1 capture the degree of imperfect altruism. The term $W^{k}\left(h_{k}(I), b_{k}, g_{k}\right)$ is the utility of a child at the time he becomes independent.

The model is completed by adding (i) a human capital accumulation technology, (ii) an aggregate production function as described earlier, and (iii) a technology to produce life expectancy given by

$$
T(g)=\bar{T}\left(1-e^{-\mu g}\right), \quad \mu>0 .
$$

This technology implies that, in the model, the maximum life span (for the average individual) is $\bar{T}$. I assume that the instantaneous utility function is

$$
u(c)=\frac{c^{1-\theta}}{1-\theta}, \quad 0<\theta<1
$$

It is necessary to choose parameter values for all the functions to draw quantitative implications from this model. Manuelli and Seshadri (2009) discuss this in detail, but the strategy is very similar to the one used to account for cross-country differences in income: Choose parameter values such that the model reproduces the appropriate moments for the United States around 2000 (which is considered a normal year).

What is the connection between productivity, $z$, and health variables? The model implies that a 25 percent increase in the level of TFP $(z)$ in a poor country (the bottom decile) would result in a tenfold increase in its output per worker and would position this country in the middle of the world income distribution. Of course, the direct effect of productivity is small, but according to the model this triggers the following changes: an average increase in schooling of almost six additional years; a 50 percent reduction in the number of children per woman; and a 40 percent increase in life expectancy. Improvements in productivity are the drivers in this exercise of increases in schooling, increases in life expectancy, and decreases in fertility. All three variables respond to the improved economic conditions.

From the perspective of the individuals in the model, it is the higher return to human capital accumulation (higher wages) that leads them to make changes in their economic and demographic choices. The mechanism through which this occurs parallels Becker's (1993) quantity-quality trade-off. An increase in productivity results in an increase in the wage rate and, hence, an increase in the return to human capital. Faced with this new set of prices, families choose to invest more in the human capital of their children and to have fewer children. The investment in human capital takes the form of more (and better) schooling and more (and better) health care. 


\section{DISEASE AND DEVELOPMENT}

Health is another dimension of human capital. In this section, I modify the model to account for the influence of a disease environment on output per worker. I concentrate on two diseases that have large impacts on sub-Saharan Africa: AIDS and malaria.

Consider the case of AIDS first. The disease environment can be described by two parameters: the infection rate and life expectancy conditional on being infected. Both events can be modeled as the occurrence of a Poisson process. Thus, healthy individuals understand when they are making their human capital investment decisions that they might become infected with AIDS and, hence, that their life expectancy could be lower in that event. In this specification, a lower life expectancy is equivalent to discounting the future more heavily.

Let the maximum life span be denoted by $\bar{T}{ }^{8}$ Then, if the probability of death over a short interval of time $d t$ is $\lambda d t$ and using $N$ to denote the length of life in years, I assume that

$$
P(N \leq a)=\frac{1-e^{-\lambda a}}{1-e^{-\lambda \bar{T}}}, \text { for } a \leq \bar{T} .
$$

This implies that the life expectancy at age $a$ is

$$
E[N \mid a]=\frac{1-e^{-\lambda(\bar{T}-a)}}{\lambda}
$$

which, given our choice of $\bar{T}$, is close to $1 / \lambda$ for a newborn.

To simplify the presentation, let $\hat{r}(x)=r+x$ and, as before,

$$
m(t ; \hat{r}(x))=1-e^{-\left(\hat{r}(x)+\delta_{h}\right)(R-t)}
$$

To describe the impact of a disease environment, consider the types of risks faced by a person who could become infected with AIDS. First, a healthy individual can become infected. Second, conditional on infection, life expectancy is lower. The following policies will have an impact on the incentives for an individual to accumulate human capital: reducing the probability of infection (e.g., increased use of protection during sexual intercourse) or increasing the availability and effectiveness of antiretroviral drugs, thereby resulting in higher life expectancy conditional on infection.

What is the mechanism through which a higher probability of death affects investment in human capital? To explore the possible answers to this question, consider how the instantaneous probability of death affects the present discounted value of any income stream, $y(t)=y$. If discounted at the rate $r$, the present value-over an infinite horizon-is simply $y / r$.

Now consider the case in which income is $y>0$ while the individual is alive and zero thereafter. In this case, the expected present discounted value of income is

$$
\int_{0}^{\infty}\left(\int_{0}^{n} e^{-r t} y d t\right) \frac{\lambda e^{-\lambda n}}{1-e^{-\lambda \bar{T}}} d n=\frac{y}{r+\lambda}\left[r-\frac{\lambda e^{-\lambda \bar{T}}}{1-e^{-\lambda \bar{T}}}\right]\left(1-e^{-r \bar{T}}\right),
$$




\section{Table 3}

\section{Lower AIDS Transmission Rate (\%)}

\begin{tabular}{lrrr} 
Country & $\Delta y$ & $\Delta s$ & $\Delta(\bar{h} e / s)$ \\
\hline Cameroon & 9.2 & 1.8 & 7.7 \\
Ghana & 4.0 & 1.2 & 2.9 \\
Malawi & 19.5 & 13.6 & 3.4 \\
Zimbabwe & 24.3 & 8.6 & 15.1 \\
\hline
\end{tabular}

which is decreasing in $\lambda$. Thus, mortality risk has an effect very similar to increasing the discount rate used by individuals. Since a higher discount requires a higher payoff to induce individuals to invest, the natural response is to invest less.

In the case of malaria-the other disease environment considered - the condition has a relatively small impact on adult life expectancy ${ }^{9}$ but a significant effect on the infected individual's ability to learn and to use human capital because of the higher morbidity associated with malaria. In this case, I use estimates of the effect on income earned by those with malaria to calibrate the learning ability parameter, $z_{h \cdot}{ }^{10}$

I have previously used the human capital accumulation model to study the impact of some changes in the disease environments associated with both AIDS and malaria for some subSaharan African countries (for details, see Manuelli, 2011). Here I describe the effects for Cameroon, Ghana, Malawi, and Zimbabwe.

Table 3 shows the percentage change in output per worker, $\Delta y$, years of schooling, $\Delta s$, and the level of human capital per year of schooling (a measure of quality), $\Delta\left(\bar{h}^{e} / s\right)$, associated with decreasing the rate of transmission of HIV/AIDS to one-half of the current value for each country.

In countries where the AIDS epidemic is relatively mild (e.g., Ghana), the gains in output are small (about 4 percent). However, in countries such as Malawi and Zimbabwe, the predicted increase in output exceeds 19 percent. Depending on the country, the model implies that the fraction of the increase in output accounted for by increases in schooling (the quantity variable) or increases in the level of human capital per year of schooling (the quality variable) varies. For example, in Malawi most of the predicted increase appears to be associated with increased years of schooling, while in Zimbabwe the largest component is the increase in quality.

Table 4 shows the results of a first attempt to evaluate the effect of increases in life expectancy for individuals infected with the AIDS virus (e.g., through increased availability of antiretroviral drugs). I study the impact of doubling the life expectancy of an infected individual. This implies that infected individuals have a higher incentive to accumulate human capital, just as healthy individuals do, because the cost of infection (which is the probability of death) is now lower.

As expected, the impact is large in Zimbabwe and Malawi, moderate in Cameroon (which has intermediate levels of AIDS and malaria), and small in Ghana. As before, there is hetero- 
Table 4

Higher Life Expectancy: AIDS (\%)

\begin{tabular}{lrrr} 
Country & $\Delta \boldsymbol{y}$ & $\Delta s$ & $\Delta\left(\bar{h}^{e} / s\right)$ \\
\hline Cameroon & 10.8 & 1.9 & 7.9 \\
Ghana & 4.5 & 1.3 & 2.8 \\
Malawi & 23.5 & 16.1 & 0.8 \\
Zimbabwe & 32.5 & 9.5 & 18.1 \\
\hline
\end{tabular}

\section{Table 5}

Lower Incidence of Malaria (\%)

\begin{tabular}{lrcc} 
Country & $\Delta y$ & $\Delta s$ & $\Delta\left(\bar{h}^{e} / s\right)$ \\
\hline Cameroon & 7.7 & 2.4 & 4.1 \\
Ghana & 13.3 & 4.6 & 2.7 \\
Malawi & 9.4 & 8.0 & 0.0 \\
Zimbabwe & 1.4 & 1.1 & 0.0 \\
\hline
\end{tabular}

\section{Table 6}

\section{Combined Effect of Interventions (\% change)}

\begin{tabular}{lccc} 
Country & $\Delta y$ & $\Delta s$ & $\Delta\left(\bar{h}^{e} / s\right)$ \\
\hline Cameroon & 23.9 & 4.0 & 18.5 \\
Ghana & 20.6 & 5.6 & 13.0 \\
Malawi & 45.7 & 24.4 & 10.9 \\
Zimbabwe & 47.9 & 11.7 & 32.0 \\
\hline
\end{tabular}

geneity in the response of quantity (schooling) or quality (human capital per year of schooling) which reflects the differences in productivity.

Table 5 shows the results of reducing the current malaria incidence by 50 percent for each country. The effect on output per worker, schooling, and the quality of human capital is significant in an environment with a high rate of malaria such as Ghana but small in Zimbabwe.

Finally, Table 6 shows the combined impact of all three interventions: halving the rates of transmission of AIDS and the incidence of malaria and doubling the life expectancy conditional on a worker being infected with the AIDS virus. The effects are very large and result in increased output per worker ranging from 20 percent to almost 50 percent. The changes in the disease environment induce individuals to increase their years of schooling and the quality of their education and OJT. 
Improvements in disease environments hold the promise of large increases in output for many sub-Saharan African countries. According to the model, such improvements would increase the demand for schooling and individuals would choose higher-quality education and jobs that allow them to better develop their skills.

\section{CONCLUSION}

The quantitative importance of human capital in understanding cross-country income differences has been and will continue to be a hotly debated issue. In this article, I show that a standard human capital framework implies large cross-country differences in the stocks of human capital driven by relatively small differences in TFP. The results suggest that (i) human capital has a central role in determining the wealth of nations and (ii) the quality of human capital varies systematically with the level of development. The model successfully captures the large variation in levels of schooling across countries, which implies that differences in the quality of human capital account for a large fraction of the cross-country differences in output. The typical individual in a poor country not only chooses to acquire fewer years of schooling but also acquires less human capital per year of schooling.

For very poor countries-in this article, some sub-Saharan African countries-the prevalence of AIDS and malaria is an additional barrier to growth. The model suggests that improvements in these dimensions will be accompanied by increases in investment in human capital.

The policy implications of this framework are clear: Policies that achieve small changes in increasing TFP and improving disease environments can have large long-run effects on output per capita. The effects are not primarily due to the direct impact of higher TFP. Rather, their indirect effects - those on the quantity and quality of schooling chosen by individualsaccount for most of the impact. The model suggests there are large payoffs to understanding which factors explain productivity differences since they play a central role in explaining development.

One important caveat is in order: The effects described in this article refer to the longrun impact on the relevant variables, and they take place over several generations. For some reasonable parameterizations, it can take more than 40 years for an economy to converge to the new steady state. Moreover, some preliminary work suggests that the dynamic adjustment path is not monotone. To be precise, it is possible for output to increase in response to an increase in productivity because some individuals will choose to invest more in human capital, and this can potentially decrease measured output. ${ }^{11}$ 


\section{APPENDIX}

An individual with human capital $h$ and age $a$ who will retire at $R \leq T$, where $T$ is lifespan, solves the following problem:

$$
V(h, a)=\max _{h(t), n(t), x(t)} \int_{a}^{R} e^{-r(t-a)}(1-\tau)\left[w h(t)(1-n(t))-p_{w} x(a)\right] d a,
$$

subject to

$$
\dot{h}(t)=z_{h}(n(t) h(t))^{\gamma_{1}} x(t)^{\gamma_{2}}-\delta_{h} h(t), \quad t \in[a, R),
$$

and I look for solutions where $n(t) \in[0,1]$.

The following proposition describes properties of the function $V(h, a)$.

\section{Proposition 1}

The function $V(h, a)$ is given by

$$
V(h, a)=(1-\tau) w\left\{\frac{m(a)}{r+\delta_{h}} h+\frac{1-\gamma}{\gamma_{1}} w^{\gamma_{2}} C^{1 /(1-\gamma)} \int_{a}^{R} e^{-r(t-a)} m(t)^{1 /(1-\gamma)} d t\right\},
$$

where

$$
C=\frac{z_{h} \gamma_{1}}{r+\delta_{h}}\left(\frac{\gamma_{2}}{p_{w} \gamma_{1}}\right)^{\gamma_{2}}
$$

and

$$
m(a)=1-e^{-\left(r+\delta_{h}\right)(R-a)} .
$$

\section{Proof}

The Hamilton-Jacobi-Bellman equation corresponding to that problem is

$$
r F(h, a)=\max _{n, x}(1-\tau)\left[w h(1-n)-p_{w} x\right]+F_{h}(h, a)\left[z_{h}(n h)^{\gamma_{1}} x^{\gamma_{2}}-\delta_{h} h\right]+F_{a}(h, a)
$$

with boundary condition

$$
F(h, R)=0 .
$$

A direct calculation shows that equation (A.1) satisfies equation (A.2) and the boundary condition.

It is easy to show that the optimal solution has the property that

$$
n(a) h(a)=w^{\gamma_{2} /(1-\gamma)} C^{1 /(1-\gamma)} m(a)^{1 /(1-\gamma)},
$$

and this implies that effective time invested in OJT declines quickly with tenure at the same time the level of human capital increases. It also shows that when the wage rate is higher, individuals are more willing to invest in training. 


\section{NOTES}

1 There are small differences across countries in the average return to schooling, but the estimates that follow are robust to those differences. For some issues measuring this return, see Card (2001).

2 See Klenow and Rodríguez-Clare (1997) for a similar view and Caselli (2005) for a good survey of alternative measures of the contributions of TFP and human capital to growth.

3 For a related model, see Erosa, Koreshkova, and Restuccia (2010).

4 This is simply a variant of Ben-Porath (1967). On the impact of school quality-here proxied by $x_{5}$-on the returns to education, see Card and Kruger (1992); for evidence in a relatively poor country, see Case and Yogo (1999). For a survey, see Hanushek (2006).

5 This assumption effectively accepts the notion that capital market imperfections are not critical. Even though it is a simplifying assumption, this seems the natural first step toward building a good model of human capital accumulation.

6 This notion of wage is not equivalent to measured hourly wages. To be specific, the hourly wage of a worker who has human capital $h$ is $w h$. Thus, in this view, wage differences across workers in the same environment are driven by differences in human capital.

7 The elasticity that can be inferred from Table 2 is much higher, around 9.4. The reason is that those values reflect changes in TFP and demographic variables.

8 As this parameter is measured in years, it seems that a reasonable estimate is $\bar{T}=120$.

9 It has a significant impact on child mortality; but in this model I focus on individuals who reach school age, and at this point the mortality impact of malaria is lower.

10 See the details in Manuelli (2011).

${ }^{11}$ Of course, if investment in human capital through schooling and OJT were included in the national income accounts, output would not decrease. However, these forms of investment are unmeasured.

\section{REFERENCES}

Barro, Robert J. and Becker, Gary S. "Fertility Choice in a Model of Economic Growth." Econometrica, March 1989, 57(2), pp. 481-501.

Barro, Robert J. and Lee, Jong-Wha. "A New Data Set of Educational Attainment in the World, 1950-2010." NBER Working Paper No. 15902, National Bureau of Economic Research, April 2010;

http://www.nber.org/papers/w15902.pdf.

Becker, Gary S. Human Capital: A Theoretical and Empirical Analysis, with Special Reference to Education. Third Edition. Chicago: University of Chicago Press, 1993.

Ben-Porath, Yoram. "The Production of Human Capital and the Life Cycle of Earnings." Journal of Political Economy, August 1967, 75(4 Part 1), pp. 352-65.

Bils, Mark, and Klenow, Peter J. “Explaining Differences in Schooling Across Countries." Working paper, University of Chicago, January 2000.

Bils, Mark and Klenow, Peter J. “Does Schooling Cause Growth?” American Economic Review, December 2000, 90(5), pp. 1160-83.

Card, David. "Estimating the Return to Schooling: Progress on Some Persistent Econometric Problems." Econometrica, September 2001, 69(5), pp. 1127-60.

Card, David and Krueger, Alan B. "Does School Quality Matter? Returns to Education and the Characteristics of Public Schools in the United States." Journal of Political Economy, February 1992, 100(1), pp. 1-40.

Case, Anne and Yogo, Motohiro. "Does School Quality Matter? Returns to Education and the Characteristics of Schools in South Africa." NBER Working Paper No. 7399, National Bureau of Economic Research, October 1999; http://www.nber.org/papers/w7399.pdf. 


\section{Manuelli}

Caselli, Francesco. "Accounting for Cross-Country Income Differences," in Philippe Aghion and Steven N. Durlauf, eds., Handbook of Economic Growth. Volume IA. Chap. 9. Amsterdam: Elsevier BV, 2005, pp. 679-741.

Erosa, Andrés; Koreshkova, Tatyana and Restuccia, Diego. “How Important Is Human Capital? A Quantitative Theory Assessment of World Income Inequality." Review of Economic Studies, 2010, 77(4), pp. 1421-49.

Hall, Robert E. and Jones, Charles I. “Why Do Some Countries Produce So Much More Output per Worker Than Others?" Quarterly Journal of Economics, February 1999, 114(1), pp. 83-116.

Hanushek, Eric A. "School Resources," in Eric A. Hanushek and Finis Welch, eds., Handbook of the Economics of Education. Volume 2. Chap. 14. Amsterdam: Elsevier BV, 2006, pp. 865-908.

Klenow, Peter J. and Rodríguez-Clare, Andres. "The Neoclassical Revival in Growth Economics: Has It Gone Too Far?" in Ben S. Bernanke and Julio J. Rotemberg, eds., NBER Macroeconomics Annual 1997. Volume 12. Cambridge, MA: 1997, pp. 73-114.

Manuelli, Rodolfo E. "Disease and Development: The Case of Human Capital.” Working Paper No. 2011-008, Human Capital and Economic Opportunity Global Working Group, November 2011.

Manuelli, Rodolfo E. and Seshadri, Ananth. "Explaining International Fertility Differences." Quarterly Journal of Economics, May 2009, 124(2), pp. 771-807.

Manuelli, Rodolfo E. and Seshadri, Ananth. "Human Capital and the Wealth of Nations." American Economic Review, September 2014, 104(9), pp. 2736-62.

Parente, Stephen L. and Prescott, Edward C. Barriers to Riches. Cambridge, MA: MIT Press, 2000.

Psacharopoulos, George and Patrinos, Harry A. "Returns to Investment in Education: A Further Update." Education Economics, August 2004, 12(2), pp: 111-34.

United Nations. World Population Prospects: The 2012 Revision. New York: United Nations, Department of Economic and Social Affairs, Population Division, 2013. 